\title{
NUNCA FORAM ACIDENTES, SEMPRE SÃO DESASTRES E CRIMES: NARRATIVAS, DISPUTAS E RESISTENCIAS NA ZONA DE SACRIFÍCIO DE BARCARENA
}

\author{
IT WAS NEVER ACCIDENT, IT IS ALWAYS DISASTERS AND CRIMES: \\ NARRATIVES, DISPUTES AND RESISTANCE IN THE BARCARENA \\ SACRIFICE AREA
}

Eunápio Dutra Carmo ${ }^{1}$

\begin{abstract}
RESUMO
O artigo analisa a atuação do movimento social Barcarena Livre na ampliação das formas de resistências para garantir os direitos territoriais dos moradores, comunidades tradicionais e ribeirinhas de Barcarena. Problematiza, também, os conflitos socioambientais, dando destaque para o contexto de avanço do modelo capitalista de produção da mineração e para as formas de enfrentamentos dos movimentos sociais em Barcarena. A zona de sacrifício e os desastres são inerentes ao conjunto das ações de ordenamento territorial pensado por governos e entidades do mercado. Apoia-se, criticamente, em autores como Castro (2017), Zhouri; Bolados e Castro (2016), Valencio (2007), Gudynas (2016). Nossas análises permitem entender que o Movimento Barcarena Livre tem produzido contra-informação e pautado o tema dos desastres numa perspectiva contra-hegomônica e, ao mesmo tempo, há atravessamentos nas suas narrativas em direção das disputas políticas e epistêmicas que exigem novas percepções dos processos de invisibilidade de comunidades ribeirinhas e quilombolas.
\end{abstract}

Palavras-chaves: Movimentos sociais; Resistências; Narrativas.

\section{ABSTRACT}

The article analyzes the performance of the Barcarena Livre social movement in expanding the forms of resistance to guarantee the territorial rights of residents, traditional and riverside communities in Barcarena. It problematizes socio-environmental conflicts, highlighting the context of advancing the capitalist model of mining production and the ways of confronting social movements in Barcarena. The sacrifice zone and disasters are inherent to the set of territorial planning actions designed by governments and market entities. It is supported, critically, by authors such as Castro (2012), Zhouri; Bolados e Castro (2016), Valencio (2007), Gudynas (2016). The Barcarena Livre movement has produced counter-information and guided the topic of disasters in a counter-hegemonic perspective

\footnotetext{
${ }^{1}$ Atualmente é Professor Adjunto do Curso de Serviço Social e Coordenador de Pós-Graduação e Pesquisa da UFPA-Campus Marajó Breves. Doutorado em Educação pela Pontifícia Universidade Católica do Rio de Janeiro e Pós-Doutorado em Desenvolvimento Socioambiental do Programa de Pós-Graduação em Desenvolvimento Sustentável do Trópico Úmido (PPGDSTU) pelo NAEA/UFPA. e-mail: eunapiodocarmo@gmail.com
} 


\section{Revista \\ Debates Insubmissos}

and, at the same time, there are crossings in their narratives towards political and epistemic disputes that demand new perceptions of the invisibility processes of riverside communities and quilombolas.

Keywords: Social movements; Resistances; Narratives.

\section{INTRODUÇÃO}

Os movimentos sociais tem imprimido uma narrativa permanente de denúncia e resistência ao sistema de mineração enraizado no Brasil. No âmbito nacional, o Movimento dos Atingidos pela Mineração (MAM) e o Movimento dos Atingidos por Barragens (MAB) têm buscado formas de enfrentamento à altura da disputa política no campo hegemônico da comunicação que privilegia o mercado. Os motes "O lucro não vale a vida" e "Somos todos atingidos", criados pelo MAM e MAB em 2019, são exemplos emblemáticos de estratégias do debate, fundamentais para "físsuras" provocadas na hegemonia da narrativa. Na Amazônia, não tem sido diferente. Diante da recorrência dos desastres provocados pela mineração, os movimentos sociais forjam narrativas que apontam o embate político sobre a atuação da mineração na região e os interesses econômicos que revelam relações de poder e conflitos socioambientais. O Movimento Barcarena Livre constitui-se em um movimento social que tem assumido um papel importante na luta por direitos territoriais. As disputas políticas e epistêmicas estão dentre as estratégias da organização social do movimento. A atuação em rede com MAM e MAB, não obstante as agendas próprias, demostra uma importante articulação entre que combina estratégia de luta e cultura política.

Com a recorrência e o volume de danos, riscos e crimes provocados pelos territórios da mineração em Minas Gerais (Samarco e Vale/BHP) e Pará (Hyro-Alunorte), o Brasil tornou-se o país com maiores desastres socioambientais do planeta nos últimos tempos (PASSARINHO, 2019). Nos municípios de Mariana, Brumadinho e Barcarena, que sofreram com os desastres da mineração, a atuação dos movimentos sociais é marcada por acirramentos e lutas políticas, pois, até hoje, se prolongam as afetações no tempo e espaço (GUDYNAS, 2016). Está-se diante de uma disputa política, mas que também é, essencialmente, epistêmica. A "fissura" na bolha tecnológica é real. O sentimento de antimeração se alastra e, com ele, discussões sobre o esgotamento e saturação de um modelo produtor de desastres que vem ganhando visibilidade 
As comunidades tradicionais (ribeirinhos, quilombolas e indígenas) têm resistido aos ataques, e os movimentos sociais têm atuado em rede protagonizando agendas de luta com atividades políticas com produção de contra-informação e realização de manifestações e campanhas que têm ganhado as ruas e as redes. Há dois aspectos da centralidade deste enfretamento que são eixos estruturantes da comunicação que organiza e orienta as narrativas dos movimentos sociais:1) aprofundar as múltiplas violências sociais e ambientais que são inerentes à natureza do sistema de mineração; 2) colocar em cheque a discussão tecnológica e puramente técnica dos desastres da mineração e afirmá-los como processos sistêmicos e prolongados.

É nessa perspectiva que o artigo tratará das ações do Movimento Barcarena Livre no ambiente de disputas, atuação política e organização das lutas em Barcarena. Inicia fazendo um panorama do tenso contexto sociopolítico e econômico no município. Posteriormente, são discutidos os elementos da fase neoextrativista do modelo de produção em Barcarena e as condições de zona de sacrifício criadas para região. Prossegue, problematizando quem defende e porque defende as ideias de acidentes e desastres-crimes na região, ambos interesses são pautados por projetos políticos e compreensão do papeis nas disputas políticas. Em seguida são apresentadas as questões metodológicas que, por sua vez, dá base para o item seguinte, que se ocupa da análise da atuação do Movimento Barcarena Livre e suas estratégias de atuação. Nas considerações finais, serão tecidos comentários sobre às agendas de luta do campo democráticopopular.

\section{BARCARENA REPRODUÇÃO DO CAPITAL E PRODUÇÃO DA RESISTÊNCIA}

O município de Barcarena, localizado na região Norte do Brasil, está a $40 \mathrm{~km}$ de Belém, capital do Estado do Pará e ocupa uma área de $401 \mathrm{~km}^{2}$, sendo um dos municípios de grande expansão na Amazônia Oriental ${ }^{2}$. A constituição socioeconômica e política de Barcarena passou por grandes transformações intensificadas pelo desenvolvimento desigual que

\footnotetext{
${ }^{2}$ Espaço compreendido como porção leste da Amazônia Legal, incluindo os estados do Pará, Amapá, Tocantins e o oeste do Maranhão.
} 


\section{Revista \\ Debates Insubmissos}

corresponde, historicamente, ao processo de formação socioeconômica da Amazônia. Ambas reflexões estão apoiadas no processo de expansão do sistema capitalista baseado na propriedade privada e exploração da força de trabalho, considerados prioritários diante das vidas humanas e natureza, tendo como alvo a reprodução ampliada do capital, dos lucros financeiros e voltados para o mercado internacional. O município de Barcarena, no contexto contemporâneo das dinâmicas socioeconômicas presentes no território, passa a ser Distrito Industrial, identificando-se com os novos e acelerados processos de transformação de múltiplas dimensões que são beneficiados pelo volume de recursos disponibilizados, aumento das demandas de mercado e aparato institucional e empresarial. Tais processos, em muitos casos, são resultantes, por um lado, da ampliação dos mercados acionados pelos agentes econômicos e, por outro lado, da ação dos segmentos sociais e do poder público diante desse cenário, na medida em que todos os envolvidos querem manter o seu território no município.

Assim, atribui-se ao território a condição de espaço que é construído pelas relações sociais (SANTOS, 1996 e 2004), envolvendo diversos e diferentes grupos sociais que socioespacializam seus interesses através de dinâmicas próprias, exercendo estratégias de poder a fim de garantir a prioridade de suas atividades e projetos. Portanto, o território pressupõe disputa, conflito, negociação, assimetria, cooptação, reveladores do grau de superposição, desigualdade e complementariedade num intrincado campo de forças composto de "nós, malhas e redes" (RAFFESTEIN, 1993, p. 33), reveladores da complexidade socioeconômica e política presente em municípios amazônicos, como se constata em Barcarena.

Evidencia-se que os territórios e seus ecossistemas estão sob ameaças permanentes, ou seja, a vida corre riscos em se tratando da própria racionalidade dos sujeitos impressa nos território e as suas diferentes formas pelas quais o trabalho é realizado na pesca, caça, plantio, de identificação de recursos que alimentam seu sistema de preservação da saúde e de curas associado à percepção e atribuição no mito e no simbólico (CASTRO, 2000). Numa abordagem relacional e transescalar (SAQUET, 2007) e na direção do que foi reafirmado sobre o território enquanto dimensão de organização da vida social e cultural, a totalidade do ser social é duramente atingida pelos desastres e crimes da mineração, agravando um fato de primeira 
ordem: desterritorialização dos povos e comunidades (HAESBAERT, 2004). Trata-se da gestão territorial hegemônica para expansão econômica capitalista em Barcarena

O processo de integração da região pela via do mercado como determina o sistema mundo-capitalista coloca regiões como América Latina na periferia do capitalismo, resultante da divisão internacional do trabalho (BRANDÃO, 2013; CASTRO, 2013). Toda essa arquitetura e cadeias de produção tem como eixo o papel do Brasil como um dos maiores países de mineração do mundo, sendo considerado um dos maiores player do mercado global (International Trade Center, 2017), e Barcarena tem um conjunto de empreendimentos com consideradas posições no mercado internacional: Albrás/Alunorte (sob o comando da Hydro), Imerys Rio Capim Caulim, Alubar Usipar, Votorantim, Bunge, dentre outras. No caso da Hydro-Alunorte, maior refinaria de alumina do mundo (DNPM, 2016), há uma certa ostentação desse título, o que também é justificada pela contribuição da mineração no PIB. Os agentes econômicos que despontam são megaempreendimentos da mineração, grandes redes logísticas/portuárias e grupos empresariais de prestação de serviço. Tais agentes tem atuado em cadeia e com agenda de negócios complementares e têm influência política nos processos de intervenção na dinâmica territorial da região.

O contraponto desse cenário revela que as comunidades ribeirinhas, quilombolas, pequenos agricultores, pescadores e moradores, de uma geral, (r)existem e teimam com seus modos de vida, de ser e saber. Continuam sendo a maioria, ou seja, aqueles que têm vínculos históricos com marcadores ancestrais e memórias sociais associadas aos modos de vida e relações sociais com a terra, rios, mata e floresta. Muitos desses segmentos têm se organizado e participado de movimentos sociais, configurando-se em agentes sociais que pautam suas lutas contra os deslocamentos compulsórios, problemas socioambientais, desestruturação cultural resultante da mobilidade do capital com "cara" de desenvolvimento. Este é um exemplo emblemático dos processos complexos de disputa dos territórios envolvendo a ação dos megaempreendimentos de mineração e comunidades tradicionais/movimentos sociais. Verifica-se um movimento de confronto que coloca em xeque concepções diferenciadas de território, onde questiona-se a intervenção do poder econômico e são estimuladas as iniciativas 
de resistência. É o embate entre agentes econômicos e agentes sociais com suas alianças que conformam conflitos territoriais, reconfigurando suas lutas e ações na adoção de redes sociais e políticas em projetos ampliados de resistência e outras agendas de direitos sociais e territoriais.

Por isso, as vias de organização dos grupos sociais expandem-se para além das experiências, notadamente, conhecidas originadas dos sindicatos. Há uma especificidade, inclusive na forma de resistir, em função da maneira de se relacionar com o território, o que estimula pautas diferenciadas, mas convergente com a garantia da cidadania e direitos ampliados, marca histórica da luta dos movimentos sociais (GOHN, 1992; 1997). Os movimentos sociais na Amazônia, especialmente aqueles ligados aos territórios destruídos pela invasão dos megaempreendimentos da mineração, tem forjado novas institucionalidades materializadas em atuação em rede, trabalho associações colegiadas e produção de contrainformação (CARMO, 2017; CARMO, HAZEU, COSTA E FIALHO NASCIMENTO, 2017; HAZEU, COSTA E FIALHO NASCIMENTO, 2019). Em geral, essas iniciativas têm conseguido a afirmação das identidades como projeto social e estratégia de luta e intervenção nos territórios.

O debate acerca dos temas território e redes são essenciais para a compreensão do ordenamento territorial que legitima a ideologia do desenvolvimento, pois o mesmo precisa parecer aceito, discutido e participativo no âmbito do sistema territorial. Para Raffestein (1993), o sistema territorial corresponde ao campo de relações de envolvendo Estado, empresas/organizações e indivíduos. São dessas relações com as dinâmicas políticoeconômicas que formam-se malhas, nós e redes, assim compreendidos: a) malhas - representam conexões, ligações heterogêneas entre diferentes atores sociais; b) nós - são pontos de encontro de relações sociais, sendo interdependentes podendo estabelecer comunicação entre si e; c) redes - representa ligação entre dois ou mais atores sociais; “[...] a rede faz e desfaz as prisões do espaço, tornado território: tanto libera como aprisiona" (RAFFESTEIN, 1993, p. 204). É a partir da confluência de malhas, nós e redes que se explica a ideia de "tramas" contemporâneas em jogo para viabilizar a agenda econômica. Do ponto de vista da integração ao mercado, tudo 
aquilo que inviabiliza esta integração é considerado "empecilho", "atraso". Neste cenário, as comunidades ribeirinhas reconfiguram processos políticos quando (r)existem e se organizam, Para Brandão (2012, p. 53): "Existe assim, um processo de busca e seleção por pontos do espaço que ofereçam maior capacidade de apropriação privada de rendimentos e onde "valorizar o valor' seja mais fácil”.

O desencadeamento de estratégias de racionalidade produtiva dos agentes econômicos aliado a mecanismos políticos de modernização nas relações público e privado vem se ampliando e, se atualizando, simultaneamente, com as mudanças nos cenários macroeconômicos, principalmente considerando as estratégias de expansão e eficiência produtiva dos megaempreendimentos minerários instalados no município que vem provocando aos seguintes acontecimentos na perspectiva dos "efeitos-derrame": reconfiguração do espaço; instalação de novos micro empreendimentos, desastres e crimes socioambientais, desapropriação de áreas, remanejamento de famílias, mudanças das forças políticas, coletivos de resistências, desaparecimento e formação de outras comunidades, atuação de novas organizações da sociedade civil. Todos esses processos representam "manifestações no espaço da valorização e da riqueza são altamente discriminatórias" (BRANDÃO, 2012, p. 53).

\section{NEOEXTRATIVISMO E ZONA DE SACRIFÍCIO EM BARCARENA}

No período de 2000 a 2010, ocorreu o grande boom de commodities que correspondeu a grande procura no mundo por grãos, minérios, metais e água, puxado pelo elevado consumo da China, líder na corrida por investimentos na economia de baixa valor agregado. Com a crise imobiliária de 2008, iniciou-se um processo de recessão e a demanda começa a dar sinais de queda que vão marcar o final da primeira década até hoje, configurando o período pós-boom das commodities (ZHOURI, BOLADOS e CASTRO, 2016). As regiões periféricas produtoras de commodities, como é o caso do Brasil, que tem suas dinâmicas econômicas marcadas pela geopolítica mundial dos recursos naturais, sentiram as mudanças do cenário econômico mundial e os reflexos nas formas extração, produção, distribuição e comercialização dos recursos naturais (COELHO, 2017). Em Barcarena não foi diferente, houve a expansão do 
sistema de mineração como demanda da fronteira de acumulação do capital via o aprofundamento da extração e saque dos recursos naturais (CARMO, CASTRO e PATRÍCIO, 2015).

Tais processos contextualizam o modelo neoextrativista da mineração na economia internacional, ancorados nas concepções de desenvolvimento para região que, por sua vez, estavam sempre relacionadas com a integração à economia brasileira, estimulando o mercado. Esta ideia estava assentada na análise de que a integração da Amazônia ao mercado diminuiria as desigualdades inter-regionais. Dessa forma, a Região Amazônica passa, de fato, a contribuir para reprodução do capital em escala nacional consagrando o modelo de desenvolvimento desigual que subordina todos os processos da dinâmica social pré-existente aos vetores da reprodução do capital e às agendas do modelo desenvolvimentista do Estado centrada na privatização e produção de commodities (CASTRO, 2017).

Para Brandão, a seletividade do território implica em adoção de estratégias do capital: “onde o valor gera mais valor” (BRANDÃO, 2012, p. 53). Essa é lógica do desenvolvimento e crescimento econômico, mas que precisa se fazer legitimar, por essa razão o Estado é uma agente institucional importante. É necessário entender que "o capital não somente produz o espaço em geral, mas também produz as reais escalas espaciais que dão ao desenvolvimento desigual a sua coerência (SMITH apud BRANDÃO, 2012, p. 53/54). É preciso que a colonialidade do poder (QUIJANO, 2011) tenha aparência de legalidade para "executar as decisões que vem de fora" e o "resultado da exploração econômica ser para fora" (CASTRO, 2017, p. 8). A colonialidade do poder está associada a uma ideia de permanente dependência e subserviência assegurando a manutenção de países, como Brasil, na condição de economia comoditizada, baseada nos bens primários.

Nesta direção, a economia do saque sofisticada tecnológica e institucionalmente como neoextrativismo, segundo Milanez e Santos (2011)

[...] a ideia de neoextrativismo corresponderia a uma reconfiguração do extrativismo, conceito cunhado para definir um conjunto de estratégias de desenvolvimento ancoradas em um grupo de setores econômicos que removem um grande volume de recursos naturais para comercialização após nenhum ou quase nenhum processamento (MILANEZ; SANTOS, 2013, p.121). 


\section{Revista \\ Debates Insubmissos}

Para esses autores, o commoditização das regiões periféricas promovem sérios problemas socais e a disputa e conflito pela terra a tensão permanente. O território onde estão os grupos e povos tradicionais é a questão central desta disputa (CASTRO, 2010) em cenários de crise financeira e a necessidade de aumento da produção de bens primários para o mercado internacional.

Todo esse processo de universalização e mobilidade do capital se espacializa de diversas formas e interesses, gerando danos múltiplos e desorganizando as estruturas sociais préexistentes. É nesse contexto que são produzidos os desastres e crimes sociais ambientais como resultante da espacialização do capital. Nas palavras de Brandão (BRNADÃO, 2012, p. 52): “É inconteste que o movimento de acumulação de capital se processa, em sua expressão espacial, de forma mutável, parcial, diversa, irregular e com alta seletividade". No caso da Amazônia e, por conseguinte, Barcarena, a dimensão espacial do desenvolvimento acena para a "natureza desigual e combinada de desenvolvimento capitalista, envolvendo dominação e irreversabilidade, próprias da polarização" (BRANDÃO, 2012, p. 31). Os anos 1980 foram determinantes para a mudança da paisagem espacial e humana dos municípios amazônicos. $\mathrm{O}$ caráter hegemônico dos planos de gestão territorial, expressões dos programas e planos de desenvolvimento, oriundos desses processos, é resultante da prática assimilacionista vinculados aos programas de desenvolvimento do governo federal.

Os processos de desenvolvimento precisam ser apreendidos na perspectiva histórica e diante dos novos processos de ocupação, apropriação e uso do território a partir da realidade socioeconômica local e suas interações com os mercados globais e internacionais, a qual implica em ampliar o contexto da abordagem para melhor captura da complexidade social e das disputas que descentralizam as relações de poder. Nessa direção, a gestão territorial, sendo uma construção social conflituosa e inacabada, está sempre se refazendo quando processos de reestruturação econômica redesenham os espaços e as territorialidades humanas, como vem ocorrendo em Barcarena, cujo território é considerado distrito industrial na Amazônia Oriental, sendo, portanto, fundamental para geoestratégia global da economia de mineração na região. Mais do que isso, Barcarena é uma zona de sacrifício (ZHOURI; BOLADOS e CASTRO, 
2016). Ou seja, em Barcarena tudo é permitido e corresponde a uma área de extensas cadeias de produção para gerar divisas e lucro para o capital, implicando em suportar desastres socioambientais, desregulamentação, ausência de fiscalização, doenças, mortes, pois todos são considerados como efeitos colaterais do "desenvolvimento".

Esses vetores contextualizam as novas disputas, que, por sua vez, geram novas dinâmicas internas, conexões e significados diante dos processos de reestruturação vigentes, haja vista que a exploração dos recursos naturais em territórios considerados como áreas estratégicas coloca em confronto agentes diversos com histórica atuação na região. Esses agentes conquistam ou perdem territórios, tencionando a região em muitos conflitos territoriais. Dentre as principais consequências desses conflitos são os desastres. Na literatura, os desastres relacionados à água são problemas estruturais no Brasil, isso aponta para, aproximadamente um quarto do total dos municípios brasileiros fossem passíveis, anualmente, de sofrerem algum problema de destruição (VALENCIO, 2007). Os dados em relação aos desastres relacionados ao vazamento de barragens são graves: oitocentas ocorrências de rompimento de 2001 a 2011 Esse quadro é debatido pelos autores para contrariar a linha de desnaturalização dos desastres socioambientais e interpretá-los a partir das estruturas sociais e econômicas adotadas por modelos econômicos que geram inseguranças e vulnerabilidade para grupos sociais, percebendo-os como "construção social do risco" (ACSELRAD, 2002), como ocorre em Barcarena. Nesse sentido, os desastres são socialmente produzidos:

Ao longo do século XX e, mais particularmente, nos últimos 50 anos a exposição das pessoas aos riscos de desastres vem crescendo no Brasil e no mundo mais rapidamente do que as capacidades de redução da vulnerabilidade, resultando em intensos e extensos (no tempo e no espaço) impactos (FREITAS; SILVA; MENEZES, 2016)

Na perspectiva da sociologia dos desastres (MARCHEZINI, 2017; VALENCIO, 2014) e nas discussões envolvendo modelos econômicos da mineração, desastres socioambientais e adoecimentos prolongado de populações que vivem na "zona de sacrifício" de Barcarena. Essa interface desastres e problemas sociais é estrutural em Barcarena na medida em que o município, recorrentemente, sofre danos ambientais em razão de acontecimentos desta ordem. Anualmente, o município vem presenciando este tipo de dano em seu território. Em 2018, houve 


\section{novistet

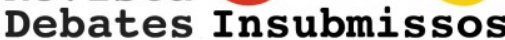

o rompimento da bacia de depósito de resíduos sólidos (DRS 2) da Hydro-Alunorte que despejou uma grande quantidade de rejeitos industriais com vários elementos químicos, gerando inúmeros "efeitos-derrame" (GUDYNAS, 2016) em Barcarena e Abaetetuba. A lama tóxica atingiu as comunidades São João, Burajuba, Sítio Conceição, Cupuaçu Boa Vista e São Lourenço Gibiriê, todas remanescentes de quilombos e seus territórios sofreram danos, em alguns casos, irreversíveis. Isso porque foi constatada a presença de chumbo, sódio e nitrato na amostra de água analisada pelo Instituto Evandro Chagas (LIMA, 2018). Também foi identificada, pelo mesmo estudo, a presença de $25 \%$ de alumínio acima do permitido para a saúde humana. Toda essa contaminação tóxica atingiu, principalmente os rios Murucupi e Tauá e os igarapés Bom Futuro e Burajuba. O consumo de água ficou comprometido e os poços artesianos foram danificados, somado à perda de hortas e animais de criação. Os danos à saúde (pulverização de doenças) e ao meio-ambiente são irreparáveis. Por tudo isso, o desastre socioambiental da Hydro-Alunorte foi o maior ocorrido na Amazônia.

Foi nessa conjuntura de conflitos e recorrência de desastres/crimes ambientais que, em 2016, surgiu o Movimento Barcarena Livre, fruto das inquietações, mobilização e insurreição de comunidades tradicionais, trabalhadores(as), associações, centros comunitários e moradores, indignados e querendo lutar pela vida. Essas mobilizações intensificaram-se com o desastre/crime da Hydro-Alunorte em 2018. No site do movimento há uma síntese sobre o seu surgimento, descrito a seguir.

O Movimento Barcarena Livre surge a partir das articulações entre moradores de comunidades tradicionais, organizações de trabalhadores de Barcarena, pesquisadores e profissionais organizadores dos Seminários "Desastres da Mineração" realizados em Belém e Barcarena no ano de 2016. Tem como objetivo principal lutar por uma Barcarena Livre de poluição, exploração, repressão e violações de direitos humanos. Produz o Barcarena Livre Informa como instrumento de resistência e produção de contra-informação para colaborar nas lutas pelo direito legítimo dos povos, comunidades e trabalhadores de serem respeitados(as) (BARCARENA LIVRE, 2016)

O Movimento Barcarena Livre é uma força social que não pode ser contida. Suas narrativas são produto do coletivo diverso, das lutas diversas, das contradições diversas do campo minado de Barcarena. Suas ações resultam da resistência histórica de comunidades tradicionais, grupos sociais, trabalhadores, estudantes, homens e mulheres que têm pensamento 
crítico e lutam por uma Barcarena livre da exploração, da submissão e da destruição. Daí porque eles sempre estão analisando, cartografando, produzindo informações para se contrapor a uma gestão territorial hegemônica, assumidamente de cultura mineradora, produtora de desastres. A esse respeito, importante perceber o caráter multifacetado do movimento.

As primeiras inserções do Movimento Barcarena Livre demonstram a força de uma das significativas experiências de organização social em processo, pois teimam sonhar e resistir criativamente. Os espaços de decisão em Barcarena, as pautas de agendas de desenvolvimento, as reuniões e fóruns sobre a cidade e os diálogos com moradores não são mais os mesmos após a atuação do Barcarena Livre. São espaços agora em disputa: por direitos, por reconhecimento como comunidades tradicionais, pela terra, pelo meio-ambiente livre de desastres, por saúde, por dignidade. O enfrentamento com ética e conteúdo são formas de se fazer notar e incomodar a estrutura.

Aliados a isso, os grupos de pesquisa da Universidade Federal do Pará que acompanham e assessoram o Movimento Barcarena Livre têm feito um esforço teórico-prático fundamental para ressignificar pesquisas e metodologias de extensão, sendo ganho efetivo na formação mais ampliada. A conduta de atuação é pela valorização da diversidade do Movimento em sua composição por entender que a natureza das identidades reflete a própria história dos grupos sociais excluídos na Amazônia. Entende-se também que a transformação de novas realidades a partir da atuação de movimentos de resistência no município, como o Movimento Barcarena Livre, torna imperativa a necessidade da argumentação e da contra-argumentação na medida que os grupos têm que propor mudanças sociais.

Um exemplo emblemático da postura crítica, ousada e política do Movimento Barcarena Livre foi a criação do site como espaço de denúncia, informação e politização sobre os assuntos de Barcarena. Na verdade, o site vem sendo aprimorado para ser um canal de comunicação comunitária. Outro exemplo foi a carta "Por uma Barcarena livre, com justiça social e boa para viver" emitida durante por ocasião do maior desastre socioambiental ocorrido na Amazônia provocado pela Hydro-Alunorte, no município de Barcarena. Nessa carta, o Movimento faz uma análise de conjuntura local e se posiciona a favor do embargo da empresa. 


\section{nevitet

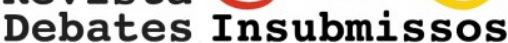

\section{Considerando:}

- A história de desastres ambientais, poluição, deslocamentos forçados e falta de investimentos nas comunidades que acompanharam a implementação dos portos, estradas, linhões, fábricas, empresas, minerodutos;

- O descaso permanente com a população e meio ambiente, comprovado pelas repetidas ocorrências de poluição, desastres ambientais e novos desmatamentos pelas empresas Hydro (Alunorte, Albrás), Imerys, Tecop, Fertilizantes Tocantins, Yara Fertilizantes, Hidrovias do Brasil, Unitapajós, ADM, entre outras, sem devido controle e punição por parte do poder público;

- A permanente luta das comunidades quilombolas, rurais e ribeirinhos, em poder permanecer nas suas terras com qualidade de vida, poder plantar, colher frutas, pescar, viver em comunidade;

- A luta dos trabalhadores das empresas e moradores por renda, emprego, condições dignas de trabalho e salários justos;

- A luta dos trabalhadores adoecidos no trabalho por reconhecimento dos seus direitos;

- A grave poluição da água (lençol freático, rios e igarapés - Dendê, Curuperé, Tauá, Murucupi, São Francisco, Pará, Furo do Arrozal...) impossibilitando acesso à água potável da população, a rios para pescar, à água para banhar;

- A poluição, os desastres ambientais e as permanentes ameaças e incertezas tem provocado graves problemas de saúde, físico e mental;

- Os planos avançados de implantar mais empresas, portos, ferrovia, linhão, termoelétrica em Barcarena, agravando a situação:

- Terminal Portuário de Uso Privado na Ilha de Urubuéa da Cargill;

- Terminal Portuário de Uso Privado e indústria de óleos vegetais no Distrito Industrial de Barcarena, da Cevital;

- Estação de Transbordo Fluvial S.A., em Barcarena;

- Termoelétrica de Celba, na área do porto da Vila do Conde

- Ferrovia Paraense (de Santana do Araguaia passando por várias comunidades até o porto da Vila do Conde);

- Terminal Portuário de Uso Privado no distrito industrial de Barcarena, da Buritirama;

- Linhão de Barcarena a Castanhal da empresa Equatorial Transmissões;

- Expansão e arrendamentos portuários no Complexo Industrial e Portuário de Vila do Conde;

Em virtude de toda essa conjuntura e a relação de uma grande parte da população com a natureza e a vida em comunidade, seus modos de viver, beber, comer, pescar e preservar sua identidade, tradições e crenças:

\section{Barcarena Livre manifesta-se e exige}

Fechamento e interdição de processos e instalações das empresas que poluem, apresentam altos riscos ou não são devidamente licenciados, exigindo adaptação da dinâmica e volume das operações a esta medida (BARCARENA LIVRE, 2019).

De um modo geral, as forças sociais que lutam e denunciam os desastres da mineração articulam-se no âmbito local, nacional e, em alguns casos, internacional. Em todas essas 
dimensões atuam na direção de uma defesa intransigente do meio-ambiente e do território diante do caos que se tornou a mineração nessa região. O Movimento Barcarena Livre soma-se a essa luta, ao mesmo tempo, é fruto da longa trajetória de enfrentamento feita pelos movimentos sociais à cultura mineradora em Barcarena. $\mathrm{O}$ estudo desse processo ilumina momentos históricos e dá visibilidade para práticas de confronto, tanto no âmbito das informações, como também nas narrativas que têm sido produzidas no campo minado de Barcarena.

\section{METODOLOGIA: APREENSÃO DAS AÇÕES DE LUTAS POR NARRATIVAS}

Os dados apresentados são frutos das manifestações em momentos de reflexão e de luta do Movimento Barcarena Livre. A coleta ocorreu no período de 2016 a 2019 durante nossa inserção, enquanto membro do Grupo de Pesquisa sobre Estado, Território, Trabalho e Mercados Globalizados (GETTAM/UFPA), nas atividades do Movimento Barcarena Livre. Em todas, o protagonismo e a formação/informação dos movimentos sociais teciam novas possibilidades e estratégias de lutas. A pesquisa está baseada na abordagem qualitativa, tendo como técnica a pesquisa de campo, valendo-se dos seguintes instrumentos: observação simples, pesquisa documental, entrevista aberta e história de vida. As categorias de análise foram construídas tendo como fio condutor os conflitos territoriais e os processos de resistência política do Movimento Barcarena Livre.

As análises serão com base na participação do Movimento Barcarena Livre em seminários, oficinas e audiências públicas. Nessas atividades, a organização social, atuação em rede e produção da contra-informação foram priorizados e ocuparam as agendas de atuação do movimento. Dentre as atividades, os seminários e as oficinas estavam vinculados às estratégias de produção da contra-informação. Por isso, que o estudo das rodas de conversa e reuniões de trabalhos foram centrais para verificar nuances desses processos de captura das informações e suas ressignificações nos corpos, vozes, sonhos, frustrações e indignações. Completa essa linha, a análise do site "Barcarena Livre - comunicação comunitária digital e resistência" como marcador de atuação nas mídias sociais. Importante destacar que as referências comunitárias estão sendo resgatadas e preservadas. Tal percepção, alimenta uma projeção de ação de 
comunicação para o caráter coletivo sempre costurado por diversidade e identidade coletivas, que forja o Movimento Barcarena Livre.

Nos anos de 2016 e 2018, o GETTAM, juntamente com os movimentos sociais, comunidades tradicionais e outras entidades, organizou três Seminários Desastres da Mineração. Muitas das discussões e depoimentos de lideranças do Movimento Barcarena Livre foram colhidas nesses seminários, bem como, as oficinas e outras produções eram amplamente deliberadas nas agendas de trabalho, construídas coletivamente nesses eventos. Outro destaque foi dado na audiência de leitura do relatório final "Danos Ambientais na Bacia Hidrográfica do Rio Pará" da Comissão Parlamentar de Inquérito (CPI) ocorrido no dia 18/12/2018 na Assembleia Legislativa do Estado do Pará (ALEPA). O trabalho de coleta de informações também foi ampliado durante a organização e divulgação do lançamento do Dossiê Desastres e Crimes da Mineração em Barcarena, em que importantes lideranças das comunidades quilombolas revelaram a apreensão diante do sofrimento, cada vez maior, diante do avanço do capital da mineração na região e, ao mesmo tempo, em que há o protagonismo de comunidades tradicionais e movimentos sociais na ação política de resistência no município.

Compreender estas atuações do Movimento Barcarena Livre está, metodologicamente, relacionado com mecanismos de organização social para a afirmação da identidade coletiva e da cultura de direitos. Também, considera-se importante a compreensão da cena política em Barcarena, em cuja arena social os agentes estabelecem estratégias e formas de apropriação. Para tal, as abordagens transescalares e multiterritoriais (SAQUET, 2017) são recomendadas por enfrentar abordagens técnicas, normativas, dominantes, homogeneizadoras e lineares, pensando novas interpretações críticas que capturam a complexidade social e as territorialidades em jogo (HAESBAERT, 2004). Metodologicamente, a captura da recomposição do campo político na região, marcado pela dominação da mineração, mas com os movimentos sociais construindo "fissuras" é uma opção para entender avanços e dificuldades nesse processo. Observa-se, por outro lado, como as formas de comunicação e resistência construídas nos coletivos e organizações sociais guardam relação direta com esta recomposição. 


\section{ACIDENTE OU DESASTRE/CRIME? QUEM FALA E OS PROJETOS QUE DEFENDEM}

Este item se ocupará da análise do processo de organização social, atuação em rede e produção da contra-informação como estratégias de resistência política do Movimento Barcarena Livre. Ao mesmo tempo, situará as abordagens dos agentes econômicos para manter a hegemonia em Barcarena que vive recorrências de desastres/crimes ambientais e não acidentes. Essa disputa é central para os movimentos sociais e vincula algumas estratégias de comunicação a duas questões-chave: Quem se beneficia com a recorrência de desastres/crimes socioambientais em Barcarena? Por que não se discute a amplitude de espaço e prolongamento no tempo dos "efeitos-derrame" dos desastres /crimes socioambientais? As respostas estão relacionadas à luta dos movimentos socioterritoriais pela garantia dos direitos constitucionais como condição de reprodução social e cultural.

Em relação à recorrência dos desastres/crimes socioambientais, o último desastre socioambiental, ocorrido em 2018, é fruto do acúmulo de experiências administrativas, gerenciais e institucionais, os quais impõem a necessária percepção de que os desastres socioambientais são considerados como produzidos socialmente e com enorme potencial sistêmico de seus efeitos. Por essa razão, não podem ser tratados como fatos isolados ou "abalos sísmicos", descontextualizados da histórica dinâmica de descumprimento de prazos, "frouxidão" de relatórios, documentos e procedimentos na linha do "paradigma da adequação" (ZHOURI; LASCHEFSKI; PEREIRA, 2005). Os estudos de impactos ambiental parecem calcados em questões mais administrativas e perdendo qualidade técnica exigida pela legislação ambiental. Paradigma da adequação aliado a uma prática de legalizar licenças mitigadoras e compensatórias adequando-as aos interesses dos empreendimentos que buscam a aprovação das mesmas (ZHOURI; LASCHEFSKI; PEREIRA, 2005). Em muitos casos, com empreendimentos já em operação, as licenças são concedidas para expansão dos empreendimentos que precisam de novas apropriações territoriais. Nesse sentido, pode-se deduzir que os danos ambientais, sociais e culturais foram negligenciados e que poderiam ser previstos nos processos de licenciamento, mas foram secundarizados em razão da rotina de 


\section{Revista \\ Debates Insubmissos}

procedimentos, cada vez mais, simplificados e da deformação da burocracia do sistema ambiental no Estado. Nesse sentido, a produção da contra-informação do movimento social é imprescindível para proceder outras análises que ampliem as causas e os efeitos dos desastres/crimes da mineração.

A percepção ampliada dos direitos territoriais (educação, saúde, cultura e meio ambiente) e perceber as características e posicionamento dos atores nos conflitos socioambientais inerentes à construção das lutas. Isso explica como os "efeitos-derrame" reforçam a violação de direitos na região. Os danos do desastre da Hydro-Alunorte colaboraram para colocar o Brasil entre os países com maiores desastres socioambientais no mundo (ONU, 2017). Ao mesmo tempo em que expõe o Estado da Noruega, considerado um dos países mais sustentáveis do mundo, por ser o maior acionista e principal gestor dos negócios da HydroAlunorte. A percepção dessas contradições fez parte das reflexões da luta política dos movimentos sociais em Barcarena.

A cultura política dos movimentos sociais perpassa pela organização social e produção de estratégias (GOHN, 2005), como também pelas tramas tecidas no conjunto da sociedade. Das reflexões feitas aqui, as análises sobre Barcarena enquanto território de conflitos e desastres dominado pela megamineração, remete-a a ideia de região estratégica para geopolítica mundial da mineração. Logo, a produção da violência e dos desastres/crimes são inerentes ao intenso processo de beneficiamento e produção de commodities e interessa manter aos agentes manter a qualquer custo o ritmo de produção para atender aos acionistas. Portanto, a cidade de Barcarena não recebe nada em troca pelos vários problemas provocados pelo sistema de mineração. Ao contrário, percebe-se a desregulamentação e ineficiência com os dispositivos legais que asseguram a segurança da sociedade. Por essa razão, que considera-crime socioambiental contra a sociedade. Com o desastre/crime ambiental da Hydro foram mais 80 comunidades atingidas pelo desastre da Hydro-Alunorte em Barcarena, mas a empresa usa a narrativa do limite, de fronteira até a sua área de ação para desresponsabilizar-se dos múltiplos problemas que ultrapassam tempo e espaço. A mesma empresa que estimula a ação sistêmica em cadeia de valor quando projeta estratégias de excelência da produção, inclusive colocando 
em primeiro plano a satisfação dos stkaholders (conglomerados de corporações do seu nicho de atuação), que direta e indiretamente está no raio de ação da empresa, podendo influenciar na performance da mesma.

O Boletim Barcarena Livre Informa (MOVIMENTO BARCARENA LIVRE, 2016) e o Dossiê Desastres e Crimes da Mineração em Barcarena (CASTRO, CARMO, 2019) são dois exemplos, dentre outros em curso, da estratégia de produzir contra-informação em rede com a UFPA e outras entidades científicas numa perspectiva de luta epistêmica e luta política que organiza socialmente a base de mobilização e, a mesmo, tempo, revela a rede política de atuação com entidades científicas. Ambos produtos foram demandas dos movimentos sociais com intuito de subsidiar à batalha epistêmica diante do avanço do capital destrutivo da mineração, contribuindo para a qualificação do debate e a opção política em denunciar o caráter criminoso da ação das mineradoras em Barcarena. Nesse percurso denso e tenso, marcado por idiossincrasias, apenas uma constância: a vontade e disposição histórica e social de dotar Barcarena de outro projeto de cidade, desta vez, livre e humana. Dessa forma, optou-se pela percepção política e social dos desastres:

Os impactos socioambientais da mineração não são simples, nem espacialmente limitados, muito menos temporalmente restritos. Na verdade, muitos deles são ecologicamente complexos, espacialmente amplos e, por serem irreversíveis, temporalmente permanentes (MILANEZ, 2017, p. 94)

As “competências locais, presença global e capacidades incomparáveis em Pesquisa e Desenvolvimento" (HYDRO, 2020) não foram capazes de impedir um dos maiores desastres da Hydro-Alunorte (vazamento de elementos químicos da DRS2) que causou danos irreparáveis à população de Barcarena, indicados por vários pesquisadores no Dossiê Desastres e Crimes da Mineração em Barcarena. O embargo de 50\% da produção da empresa, a CPI instalada na Assembleia Legislativa, os problemas no atendimento às comunidades atingidas, para ficar nesses aspectos, acenam para uma inconteste aferição de que o sistema de mineração da empresa foi atingido frontalmente. Há um agravante: a dificuldade de a empresa admitir que houve o vazamento e, por conseguinte, a contaminação da população e rios acirra ainda mais "campo minado" e expõe a correlação de força e os interesses em disputa. 


\section{Revista \\ Debates Insubmissos}

Nesse nível de atuação da empresa, a interpretação ampliada dos processos, além de fundamental, permite sair do labirinto que condiciona análises em dimensões gerais e globais que não permitem a percepção do local, ocasionando processos de invisibilidade de comunidades ribeirinhas e quilombolas, por exemplo. Esses processos de negação, silenciamento são produzidos socialmente. Novas percepções desses movimentos se dão no campo epistêmico por se tratar de conhecimentos afirmadores dos interesses em jogo, principalmente diante do cenário de pós-boom das commodities. Como também pela postura sempre de autossuficiência das empresas mineradoras que se eximem em assumir suas disfunções e problemas crônicos, como se não houvesse outras formas de pensar, interpretar e intervir na realidade. O padrão tecnológico, marcadamente "sustentável e inovador", é o núcleo vital da atuação das mineradoras. É nítida a imposição do poder pela ideologia da modernização sem disfarçar, em muitos casos, o ar de superioridade e a empáfia quando são tratados os históricos problemas da mineração: desastres/crimes socioambientais, insegurança e adoecimento. $\mathrm{O}$ fato de atuarem com padrão internacional aparece como um escudo de autodefesa, ou seja, o mercado internacional legitima na medida em que os países compradores são considerados referência na questão ambiental. Isso tem um rebatimento direto nas relações locais, pois, nos embates políticos, a posição das empresas no mercado (Brasil é o segundo maior produtor mundial de ferro) e a referência internacional (Hydro-Alunorte maior refinaria de alumina do mundo) servem como uma espécie de orgulho para que as atrocidades continuem.

A questão inescapável como desvincular desastre de mineração diante de tanta tragédia social e ambiental e todos os esforços das corporações transnacionais agora são nessa direção. Tanto é verdadeiro que os últimos relatórios da Hydro revelam que o fator comunicação com a sociedade está entre os prioritários. A disputa do campo da comunicação coloca de um lado a narrativa da mineração como setor vital para a humanidade e com práticas sustentáveis e, do outro lado, se consolida a narrativa da antimineração (rejeição) e avança a correspondência da mineração com morte e destruição, associando essas noções a esse negócio. A aversão à mineração preocupa a governança da empresa e é centro das atenções. Aproximação com as comunidades passa a ser uma ferramenta importante para a atuação da empresa, ainda que admita fazer isso como "ajuda humanitária" (HYDRO- RELATÓRIO ANUAL, 2017). As 


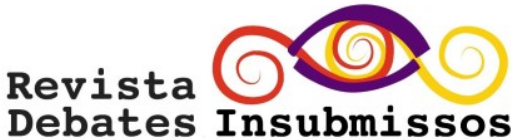

mineradoras correspondem a empresas de modelo neoextrativista, neocolonial e neoliberal que atendem aos interesses do capital financeiro por meio de novas lógicas de apropriações territoriais e recorrente aprimoramento tecnológico. Por essa razão, sofisticam a instalação de cadeias produtivas com fortíssimo potencial de injustiça e racismo ambiental para intensificar a produção, para aumentar a escala e reduzir os custos fixos.

A posição da Hydro-Alunorte a respeito do desastre ocorrido em fevereiro 2018 é de negação, e a expressão "Não foi acidente" é acintosamente usada para negar a sua responsabilidade e anunciar uma outra versão sobre o fato, o que implica uma análise mais larga sobre o tema e traz para a discussão os problemas de atuação da empresa. Aliás, a esse respeito, a consultoria Ernst \& Young (2019) recomenda que o setor atue como sistema integrado com cadeias de produção sofisticadas tecnologicamente. Ou seja, para uma performance otimizada e produtiva, a visão sistêmica e em cadeia é reconhecida e enaltecida. No entanto, quando se trata dos desastres, essa noção é afastada completamente para dá lugar às explicações mais simplistas que isolam o que chamam de "acidentes", "episódios", restringindo-os à área limite de ocorrência, operando uma visão restrita de acordo com as circunstâncias. Isso faz parte da estratégia empresarial de os desastres como problemas tecnológicos passíveis de ajustes. Reside aqui uma das principais críticas das comunidades atingidas e movimentos sociais por entenderem que existe uma cadeia de produção de desastres que se constitui em perigo constante, promotor de desarticulação e desarmonia com o meio-ambiente, interferindo em suas dinâmicas sociais, econômicas, culturais e ambientais, ocasionando desdobramentos que se espacializam em todo o território. No limite, ela é cobrada pelo crime ambiental, como está estampado nesse cartaz exibido na audiência pública em Barcarena (22/03/2018). 


\section{Revista \\ Debates Insubmissos}

Audiência Pública

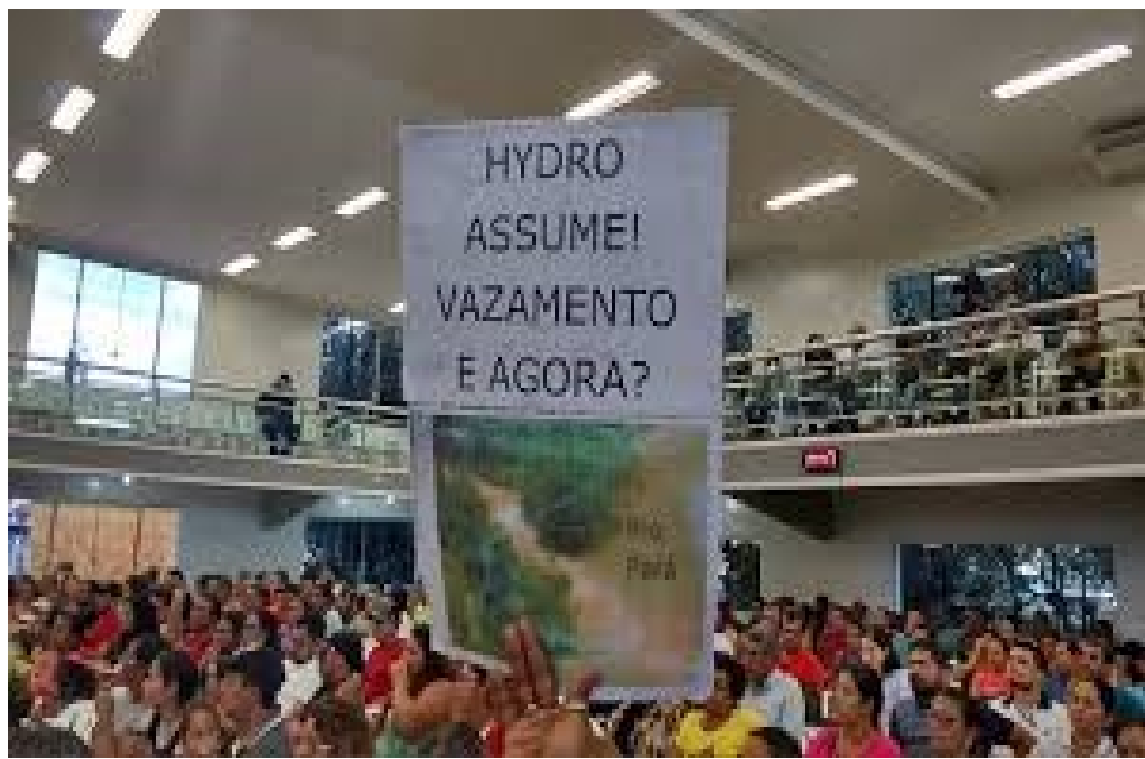

Foto: Lilian Campelo ${ }^{3}$

Os desastres socioambientais provocados por grandes mineradoras em Mariana e Brumadinho fizeram com que o sentimento de antimineração (repugnação e rejeição às empresas mineradoras) aumentasse na sociedade, cooperando para a recomposição do campo político. Nesse sentido, o slogan "Somos todos atingidos" (MAM) ganha importância porque coloca, na cena contemporânea brasileira, os limites da mineração, ganhando um importante efeito de politização dos "efeitos-derrame", múltiplas formas de violência provocadas pela mineração (GUDYNAS, 2016). Por outro lado, aceleram-se as estratégias de uma nova comunicação da Hydro-Alunorte diante desse cenário de ampliação das críticas e sentimento antimineração. Essas estratégias são constantes em seus documentos oficiais (relatórios, boletins e sites coorporativos).

Outra discussão importante para resistência política do Movimento Barcarena Livre são os limites dos desastres defendidos pela empresa. Em contraposição, entende-se que não há

\footnotetext{
${ }^{3}$ As fotos utilizadas nesse artigo são dos blogs progressistas Amazônia Real e Brasil de Fato com atuação de denúncia, diferentemente da mídia coorporativa
} 
limites para os desastres, não se pode dizer quem foi e quem não foi afetado. Esta é a posição política dos movimentos socias e entidades de luta em Barcarena. As comunidades que vivem esse dilema estão sendo enganadas. Suas territorialidades estão sendo desconsideradas, nesse momento a produção da contra-informação e da comunicação para uma resistência mais efetiva são essenciais.

Em audiência na Assembleia Legislativa do Estado do Pará para leitura do relatório final da CPI (18/12/2018), um representante assim se referiu sobre o enfrentamento político: “O nosso único e principal inimigo é a empresa. E qualquer um que tiver do lado da empresa, seja órgão pública, seja órgão estadual, federal, também será o nosso inimigo". O confronto políticoideológico é marcadamente relacionado aos atores sociais e econômicos envolvidos. A empresa passa ser considerada o principal foco dos embates políticos. Em outro momento (audiência pública em Barcarena), a empresa é cobrada pela poluição da água, um dos aspectos mais críticos da região, nas manifestações dos grupos sociais e moradores.

Audiência Pública

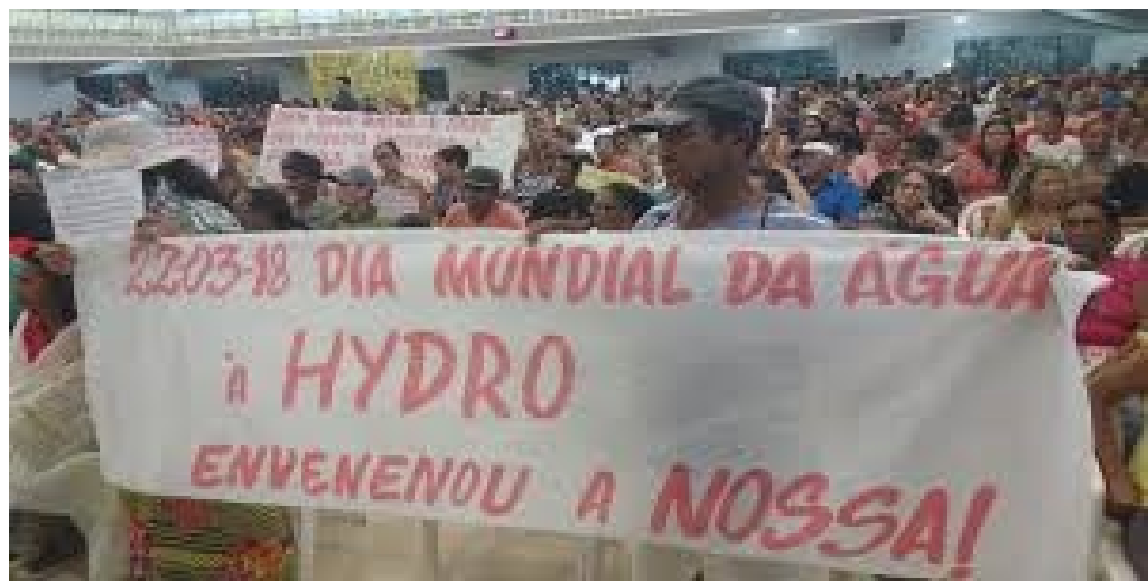

Foto: Lilian Campelo

A relação com as comunidades sempre é estremecida. A tensão é permanente. A falta de transparência da empresa aumenta a tensão. Nas audiências públicas, manifestações populares, reuniões de trabalho, é comum notar a presença de faixas e cartazes que denunciam, 
ironizam, politizam e desabafam toda uma carga de opressão, dominação e sufocamento presente na histórica exploração do espaço de Barcarena, desterritorizando-o. O Movimento Barcarena Livre tem, nesses espaços, protagonismo de fala e posicionamento político. Ou seja, os espaços institucionais acabam potencializando formas de comunicação (verbal ou nãoverbal) que transmitem mensagens de maneira direta e ganham visibilidade nas mídias. Foi assim durante todo o período de maior atenção para o desastre da Hydro-Alunorte em Barcarena. Expressões como "assassina", "culpada", "morte”, "poluição", "justiça", "condenada", dentre outras desencadeiam múltiplas frentes de embate no campo políticoideológico por se tratar de expressões denunciativas que colocam em cheque a postura da empresa como sofisticada e requintada.

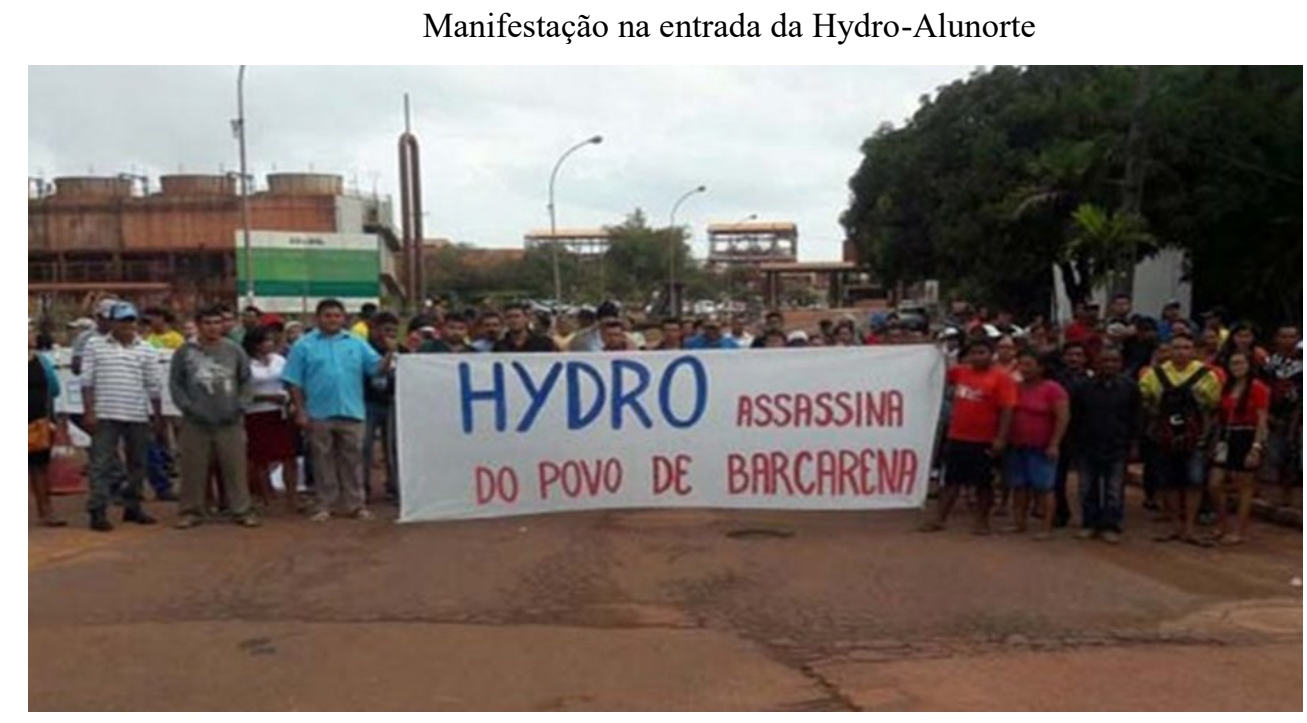

Foto: Luiz Salatino 
Audiência Pública

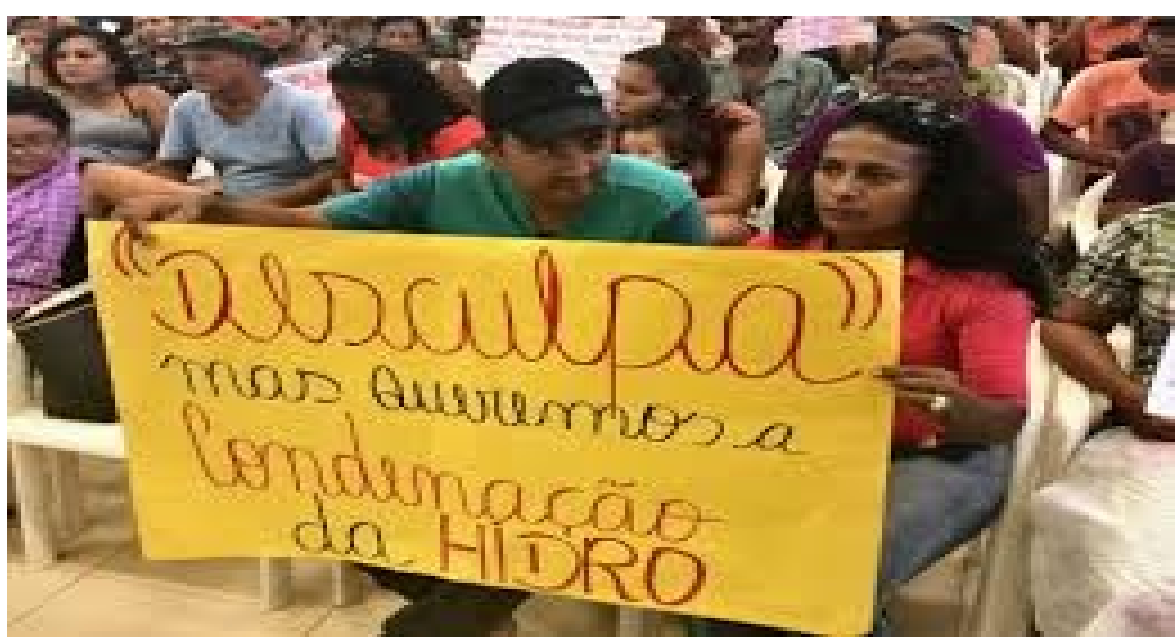

Foto: Lilian Campelo

A produção de outras narrativas que fissurem a "bolha tecnológica" da mineração é fundamental para a politização do debate e faz parte da estratégia de produção da contrainformação dos movimentos sociais, comunidades tradicionais e moradores. São forma de pautar discussões que joguem luz sobre a ineficiência do sistema de mineração no Brasil e sobre a responsabilidade do Estado nesse processo. Portanto, falar de "desastres", "crime", "dano", "risco", “adoecimentos", "insustentável”, “mortes”, “antimineração” é denúncia e, ao mesmo tempo, trabalha para a produção de sentidos da mineração que contrariam àqueles agenciados pela hegemonia do mercado. Os embates travados por empresas mineradoras e movimentos sociais no território de Barcarena são demonstrações do encontro-choque envolvendo formas de apropriação no campo de força em que as narrativas são acionadas com repertórios diversos: sustentável e insustentável, segurança e insegurança, saúde e morte, responsabilidade social e cooptação, progresso e retrocesso, maior do mundo e "assassina" são formas de afirmação das territorialidades em disputa em Barcarena. As formas de comunicação (falas, cartazes, site) tem reproduzido essa linha de enfrentamento-denúncia, construída a partir da militância dos envolvidos, seus saberes, experiências e culturas.

O Barcarena Livre afirma-se como exemplo vivo do que o compromisso social com a luta pode produzir de identidade, novas racionalidades e contra-informação. É um movimento 


\section{Revista \\ Debates Insubmissos}

de intervenção social que combina objetivos de afirmação de identidade tradicional, organização social para conquista de direitos, capacitação organizativa e formação política ideológica. O resgate e a afirmação da ancestralidade de códigos, de memórias, símbolos que revelam o cuidado, a contemplação e a inteligente relação do homem com a natureza, seu habitat, sua vida, suas relações sociais, diferentemente da relação de mercado e lucro que se constrói na dinâmica atual. Sua marca é mobilidade coletiva frente à injustiça social e procura desenvolver conhecimentos, competências e métodos necessários para a produção da lita social, pois entende-se que as circunstâncias históricas requerem processos de sistematização que organizam fatos e memórias e ordenam ideias a fim de ampliar as estratégias e as táticas de reivindicação, como forma de trabalhar coletivamente o aprendizado e dialeticamente concebida, numa perspectiva do confronto com o já estabelecido, gerando contra-hegemonia no pensar, dizer e criar. Por isso, livre, forte e coletivo são princípios vividos e concebidos nas práticas do movimento que possui uma tarefa histórica.

Os desastres são produzidos socialmente e, ao mesmo tempo, exigem a recomposição do sentido de resistência nas bases dos territórios de luta. Os corpos estão sendo constantemente violentados e, frontalmente, grupos sociais são desestruturados pela ação predatória das madeireiras na região. Ambas atuações estão, metodologicamente, relacionadas com mecanismos de organização social para a afirmação da identidade coletiva e da cultura de direitos. Dentre as práticas vivenciadas, as formas de comunicação, as disputas de narrativas e a formação de comunicação não-verbal e o site configuram-se em experiências sociopolíticas que acenam para um conhecimento concreto que vem potencializando a participação social das comunidades, não obstante todas as contradições sociais advindas de uma cidade marcada pelos desastres. Numa perspectiva contra-hegomônica e, ao mesmo tempo, relacional, há atravessamentos nas narrativas em direção às disputas políticas e epistêmicas que exigem novas percepções dos processos de invisibilidade de comunidades ribeirinhas e quilombolas, produzidos socialmente e, concomitantemente, a atuação no sentido da recomposição do campo político na região, marcado pela dominação da mineração, no entanto há reações de coletivos e organizações sociais somando ao fato do aumento do sentimento de antimineração no âmbito 


\section{Revista \\ Debates Insubmissos}

nacional. O território, nesse caso, se refaz, pois, na dinâmica dialética da história, há contramovimentos de dominação. Barcarena Livre é um deles.

\section{CONCLUSÕES}

O município de Barcarena é entrecortado por inúmeras cadeias de produção e logística envolvendo produção de caulim e beneficiamento de alumina e alumínio, além de postos de tráfego de escoamento dessa produção. Subjacentes a todos esses processos, estão presentes a desestruturação socioespacial e os desastres socioambientais irreparáveis e irreversíveis. Segundo levantamento feito conjuntamente com as comunidades da região, aconteceram desastres nos últimos anos, por isso considera-se um "campo minado". O Movimento Barcarena Livre foi forjado nessas tramas e lutas políticas em Barcarena. Ações deste movimento tem sido estratégico: organização social, atuação em rede e produção da contra-informação. Todas guardam interação entre si e promovem juntas a base da resistência política. A confrontação de interesses é histórica e estrutural para o reconhecimento dos direitos territoriais em Barcarena.

Diante da agenda de implantação de grandes projetos na região, esse processo social e a tensão estabelecida com a atuação dos movimentos sociais. Por essa razão, houve uma linha orientadora da ação-reflexão com o Movimento Barcarena Livre por ser uma ampla expressão do que sentem e a garantia da enunciação da palavra daqueles que lutam contra a degradação em curso em Barcarena. As narrativas que buscam identificar e descrever percursos históricos e as expressões e vivências com seus antecedentes e conteúdos compõem o quadro das contradições e avanços são a matriz formativa e informativa desenvolvida coletivamente pelo Movimento, tendo como foco principal as relações históricas e sociais em que grupos sociais se encontram nas estruturas de dominação do capital no município.

As dimensões tecnológicas, técnicas, administrativas da recorrência dos desastres/crimes socioambientais, entendida pelo Movimento como produto do capital minerador, são insuficientes para compreensão dos desastres enquanto fenômeno complexo e multidimensional. Nesse sentido, os campos mencionados discutem o tema dos desastres na 
perspectiva das contradições sociais na sociedade na sua relação com a natureza e dos atores envolvidos com seus interesses díspares numa disputa pelos territórios. O Movimento Barcarena Livre, em rede política com entidades científicas, pauta a vinculação do atual quadro social às dimensões políticas, sócio-históricas para o debate sobre os desastres da mineração. Por essa via, se alarga o debate e as questões ganham a dimensão interdisciplinar, ambiental e humana que a ciência contemporânea vem atuando.

As narrativas produzidas por moradores, lideranças, trabalhadores, ribeirinhos e comunidades tradicionais estão inscritas na realidade da produção social dos desastres socioambientais em Barcarena. São corpos indignados, cansados e marcados por lutas históricas que se reatualizam na medida em que voltam a ser ameaçados com a expansão de complexos industriais. O Movimento Barcarena Livre é uma força social de produção de contrainformação que encontra mecanismos de enfrentamento via comunicação verbal, não-verbal e por site. Opta por uma organização sociopolítica plural com articulação com outros movimentos sociais (MAM e MAB).

\section{REFERÊNCIAS}

ACSELRAD, H. Justiça Ambiental e Construção Social do Risco. In: ENCONTRO

NACIONAL DE ESTUDOS POPULACIONAIS, 13, 2002, Ouro Preto. Anais ... Ouro Preto: ABEP, 2002. Disponível em: http://www.abep.org.br/publicacoes/index.php/ anais/article/view/1159. Acesso em: 30 abr. 2019.

BARCARENA LIVRE - comunicação comunitária digital e resistência. Disponível em: http://culturadigital.br/barcarenalivre/quem-somos/. Acessado em 28 de janeiro de 2020.

BRANDÃO, Carlos Antonio. Território e desenvolvimento: as múltiplas escalas entre o local e o global. $2^{\mathrm{a}}$ ed. Campinas, SP: Editora da Unicamp, 2012.

CASTRO, E.; CARMO, E. D. (Ogrs). Dossiê: Desastres e crimes da mineração em Barcarena. Belém: NAEA: UFPA, 2019. 
CARMO, E. D. HAZEU, M. T., COSTA, S. M. G. DA, \& FIALHO NASCIMENTO, N. S. Barcarena livre: resistência e lutas de comunidades tradicionais frente aos desastres socioambientais da mineração. In: CASTRO, E. (Org.). Territórios em Transformação: saberes, rupturas e colonialidade. Belém: NAEA, 2017. p. 365-388.

CARMO, E. D. Desastres e tensões em Barcarena à luz de disputas territoriais. In: CASTRO, E. (Org.). Territórios em Transformação: saberes, rupturas e colonialidade. Belém: NAEA, 2017. p. 65-80.

CARMO, E. D.; CASTRO, E.; PATRÍCIO, J. Mineração e neo-extrativismo de commodities e conflitos. Novos Cadernos NAEA, v. 18, n. 3, p. 51-71, 2015.

COELHO, M. C. N. e al. Regiões de acumulação mínero-metalúrgicas e os riscos de desastres ambientais das barragens de rejeito no Brasil. ANPEGE, v. 13, n. 20, p. 83-108, 2017.

DNPM - Departamento Nacional de Produção Mineral. Classificação das barragens de mineração. Belém: DNPM, 201. Disponível em: http://www.anm.gov.br/assuntos/ pdf. Acesso em: 15 maio 2019.

Ernst \& Young. Centro Global de Mineração \& Metais. Disponível em:

https://www.ey.com/pt br/mining-metals. Acessado em: 14 de agosto de 2019

FREITAS, Carlos Machado de; SILVA, Mariano Andrade da; MENEZES, Fernanda Carvalho de. $\mathrm{O}$ desastre na barragem de mineração da Samarco - fratura exposta dos limites do Brasil na redução de risco de desastres. In: Ciência e Cultura, vol. 68 nº.3, São Paulo Jul/Set., 2016. GOHN, Maria da G. Educação Não-Formal e Cultura Política. São Paulo: Cortez, $3^{\mathrm{a} e d .,}$ 2005

GOHN, Maria da G. Movimentos Sociais e Educação. São Paulo: Corte, 1992.

GOHN, Maria da G. Teoria dos Movimentos Sociais. São Paulo: Loyola, 1997.

GUDYNAS, E. “Extractivismos en America der Sur: conceptos y sus efectos derrame”. In: A. Zhouri, P. Bolados, E. Castro (eds.), Mineração na América do Sul: neoextrativismo e lutas territoriais. São Paulo: Ed. Annablume. 2016, pp. 23-43. 
HAESBAERT, R. O mito da desterritorialização: do "fim dos territórios" à multiterritorialidade. Rio de Janeiro: Bertrand Brasil, 2004.

HAZEU, M. T., COSTA, S. M. G. DA, \& FIALHO NASCIMENTO, N. S. (2019). Comunidades tradicionais e sindicatos em conflito com estado e capital em Barcarena (PA). Argumentum, 11(1), 173-187.

HYDRO-ESTRATÉGIAS E METAS, 2017. Disponível em:

https://www.hydro.com/en/investors/reports/annual-report-2017/strategy-and-targets/ Acesso em 14 de abril de 2019.

INTERNATIONAL TRADE CENTER. Trade map: trade statistics for international business development, 2017. Disponível em: http://www.trademap.org. Acessado em 10 de mar. 2019. LIMA, M. O. et al. Avaliação preliminar dos impactos ambientais referente ao transbordo e lançamentos irregulares de efluentes de lama vermelha na cidade de Barcarena. Estado do Pará. Ananindeua: IEC, 2018.

MAM - Movimento pela Soberania Popular na Mineração Crime da Vale em Brumadinho completa um ano com 272 mortes e 11 pessoas não localizadas. Disponível em: https://mamnacional.org.br/2020/01/24/crime-da-vale-em-brumadinho-completa-um-ano-com272-mortes-e-11-pessoas-nao-localizadas/. Acessado em 30 de jan. 2020.

MILANEZ, B.; SANTOS, R. Neodesenvolvimentismo e neoextrativismo: duas faces da mesma moeda? In: ENCONTRO ANUAL DA ANPOCS, 37, 2013, Sãp Paulo. Anais ... São Paulo: ANPOCS, 2013. Disponível em: http://www.ufjf.br/poemas/files/2014/07/Milanez-2013Neodesenvolvimentismo-e-neoextrativismo-duas-faces-da-mesma-moeda.pdf. Acesso em: 19 jan. 2019.

MOVIMENTO BARCARENA LIVRE. Barcarena Livre Informa. Belém: IBASE/UFPA/ICSA/NAEA, 2016.

QUIJANO, Aníbal. Colonialidade do poder e classificação social. In: SANTOS, Boaventura de Sousa; MENESES, Maria Paula (Org.). Epistemologias do Sul. São Paulo: Cortez, 2010. p. 84130. 


\section{PLANO DIRETOR DE DESENVOLVIMENTO URBANO DE BARCARENA.}

PREFEITURA Municipal de Barcarena. Disponível em: <

http://www.barcarena.pa.gov.br/portal/legislacao?tipo=home\&titulo=PLANO\%20DIRETOR\% 20DE\%20 DESENVOLVIMENTO\%20URBANO.> Acesso em: 02/03/2019

PASSARINHO, N. Tragédia com barragem da Vale em Brumadinho pode ser a pior no mundo em 3 décadas. BBC NEWS, Londres, 29 de janeiro de 2019. Disponível em: https://www.bbc.com/portuguese/brasil-47034499. Acesso em: 25 mar. 2019.

SAQUET, M. A. Abordagens e concepções sobre território. São Paulo: Expressão Popular, 2007.

SANTOS, M.; SILVEIRA, M.L. O Brasil: território e sociedade no início do século XXI. 6.ed., Rio de Janeiro: Record, 2004.

SANTOS, Milton. A natureza do espaço. Técnica e tempo. Razão e emoção. São Paulo: Hucitec, 1996.

RAFFESTIN, Claude. Por uma Geografia do Poder. São Paulo: Ática, 1993.

VALENCIO, Norma. O desastre como desafio para a construção de uma hermenêutica boom diatópica entre o Estado e os afetados. Revista Cronos, Natal, v. 8, n. 1, p.81-100, 2007.

Disponível em: Disponível em: https://periodicos.ufrn.br/cronos/issue/view/196. Acessado em: 20 de julho de 2019 .

ZHOURI, A. BOLADOS, P. CASTRO, E.(Orgs). Mineração na América do Sul: neoextrativismo e lutas territoriais ( 1 a ed.). Coleção Cidadania e Meio Ambiente. São Paulo: Annablume, 2016.

ZHOURI, A.; LASCHEFSKI, K.; PEREIRA, D. B. A Insustentável Leveza da Política Ambiental. Belo Horizonte: Ed. Autêntica, 2005.

Submetido em: 17/03/2020

Aprovado em: 29/04/2020 